\title{
Особенности калмыцкого письменного языка XIX в. (на материале калмыцких писем И. Я. Шмидта (1800-1810 гг.))
}

\section{Евгений Владимирович Бембеев ${ }^{1}$}

\author{
${ }^{1}$ Калмыцкий государственный университет им. Б. Б. Городовикова (д. 11, ул. Пушкина, \\ 358000 Элиста, Российская Федерация) \\ кандидат филологических наук, доцент \\ iD 0000-0001-9936-221X. E-mail: galdma@yandex.ru
}

\author{
(C) КалмНЦ РАН, 2020 \\ (C) Бембеев Е. В., 2020
}

\begin{abstract}
Аннотация. Введение. В 2002 г. известные монголисты Джон Крюгер и Роберт Сервис издали книгу «Калмыцкие старинные рукописные документы Исаака Якоба Шмидта», в которой представлены факсимиле, транскрипция и перевод на английский язык эпистолярных документов, которые охватывают период с 1800 по 1810 гг. Большая часть писем - 54 из 80 - отражает переписку И. Я. Шмидта с князьями Тундутовыми, в том числе 18 - от Эрдени Тайши, 27 - от Цебека, еще 9 - от Джамба Тайши. Эти письменные памятники хранятся в архиве Общины моравских братьев г. Хернхут (Unitas Fratrum — «Объединенные братья») в папке (R.15.R.IIa № 5). Цель статьи - рассмотреть некоторые фонетические и морфологические особенности калмыцкого языка по данным опубликованных писем И. Я. Шмидта. Результаты. Язык писем И. Я. Шмидта отражает этап развития калмыцкого языка конца XVIII - начала XIX в., характеризующийся закономерным сближением фонетических и грамматических норм письменного литературного языка с живой народной речью. Материалы текстов писем показывают, что в начале XIX столетия имеет место процесс перехода сочетаний -ои и -ӧ̈̈ в долгий гласный [u:] и [ӥ:] соответственно. В языке писем И. Я. Шмидта при передаче глаголов повелительной формы 2-го лица множественного числа зафиксировано несколько случаев использования разговорного форманта -tan, вместо традиционного показателя -qtün /-qtun. Языковые процессы, связанные с редукцией кратких гласных непервых слогов слова, сокращением морфологических формантов и др., нашли свое отражение в большей или меньшей степени в тексте исследуемого памятника.
\end{abstract}

Ключевые слова: калмыцкий язык, письменные памятники, письма, И. Я. Шмидт, фонетические изменения, морфология

Благодарность: Исследование выполнено при финансовой поддержке РФФИ в рамках научного проекта № 20-512-93002 «Памятники „ясного письма“ как культурное наследие России и Китая». Материалы статьи апробированы на Международной научной онлайн-конференции «Монголоведение в начале XXI в.: современное состояние и 
перспективы развития - ІІ», проведенной при финансовой поддержке РФФИ (проект № 20-09-22004) и частичной поддержке гранта Правительства РФ (№ 075-15-20191879).

Для цитирования: Бембеев Е. В. Особенности калмыцкого письменного языка XIX в. (на материале калмыцких писем И. Я. Шмидта (1800-1810 гг.)) // Монголоведение. 2020. T. 12. № 4. С. 652-659. DOI: 10.22162/2500-1523-2020-4-652-659

UDC 811.512.37

DOI: $10.22162 / 2500-1523-2020-4-652-659$

\title{
Peculiarities of $19^{\text {th }}$-Century Written Kalmyk: A Case Study of I. J. Schmidt's Kalmyk-Language Letters, 1800-1810
}

\author{
Evgeny V. Bembeev ${ }^{1}$
}

\author{
${ }^{1}$ Gorodovikov Kalmyk State University (11, Pushkin St., Elista 358000, Russian \\ Federation) \\ Cand. Sc. (Philology), Associate Professor \\ iD 0000-0001-9936-221X. E-mail: galdma@yandex.ru
}

(C) KalmSC RAS, 2020

(C) Bembeev E. V., 2020

\begin{abstract}
Introduction. The article examines some phonetic and morphological features of the Kalmyk language traced in written monuments published by the famous Mongolists John Krueger and Robert Service in the 'Kalmyk Old-Manuscript Documents of Isaac Jacob Schmidt' (2002). The book presents facsimiles, transcriptions and translations of epistolary documents into English, which cover the period from 1800 to 1810. Most of the letters 54 out of 80 - reflect correspondence with the Baga Dorbet Princes Tundutovs, including 18 from Erdeni Taisha, 27 from Tsebek, and 9 more from Jamba Taisha. These written monuments are kept in the archives of the Moravian Brothers Community in Herrnhut (Unitas Fratrum, Eng. 'United Brothers') in folder R.15.R.IIa No. 5. Goals. The paper aims at investigating some phonetic and morphological features of the then Kalmyk language discovered in the published letters. Results. The language of I. H. Schmidt's letters reflects the stage in the development of the Kalmyk language in the late $18^{\text {th }}$ - early $19^{\text {th }}$ centuries characterized by a natural convergence of the phonetic and grammatical norms inherent to the written literary language and living folk speech. The materials of the texts show that the beginning of the $19^{\text {th }}$ century witnessed a process of transition of the combinations -ou and -ö̈ into the long vowels [u:] and [ü:], respectively. It is also noted that in words where the diphthong -iu is historically (traditionally) used, e.g., in the word alčiur — in letters it is transmitted as alčuur, which meets the requirements of live pronunciation. In the language of letters of I. J. Schmidt, when it comes to construct the imperative form of the $2^{\text {nd }}$ person plural, several cases of using the colloquial formant -tan are recorded, instead of the traditional indicator -qtün / -qtun. The past participle, which is historically formed with -qsan / -qsen affixes, also approaches colloquial forms, therefore, there are frequent cases of using -san /-sen forms, which are closer to modern Kalmyk (e.g., xara toryon irsen bolxuna 'if the black silk arrives'). Linguistic processes associated with the reduction of short vowels of non-first syllables of a word, reduction of morphological formants, etc., are reflected to a
\end{abstract}




\section{Монголоведение • Mongolian Studies • 2020 ๑ T. 12 • № 4}

greater or lesser extent in the text of the studied monument. Conclusions. Thus, the language of I. Ya. Schmidt's letters reflects the stage of development of the Kalmyk language at the end of the $18^{\text {th }}$ - beginning of the $19^{\text {th }}$ centuries characterized by a natural convergence of phonetic and grammatical norms of the written literary language and living folk speech.

Keywords: Kalmyk language, written records, letters, I. Ya. Schmidt, phonetic changes, morphology

Acknowledgments. The reported study was funded by RFBR, project no. 20-512-93002 'Clear Script Monuments as a Cultural Heritage of Russia and China. The article was presented at the International scientific online conference 'Mongolian Studies at the Beginning of the $21^{\text {st }}$ Century: Current State and Development Prospects - II' funded by RFBR (project no. 20-09-22004) and Government of Russia (grant no. 075-15-2019-1879).

For citation: Bembeev E. V. Peculiarities of $19^{\text {th }}$-Century Written Kalmyk: A Case Study of I. J. Schmidt's Kalmyk-Language Letters, 1800-1810. Mongolian Studies (Elista). 2020. Vol. 12. No. 4. Pp. 652-659. (In Russ.). DOI: 10.22162/2500-1523-2020-4-652-659

\section{Введение}

История языка состоит из двух основных дисциплин: исторической грамматики и истории литературного языка. Первая из них, имеющая условное название, включает в себя и историческую фонетику с морфологией и синтаксисом, и историческую лексикологию с рядом специальных дисциплин (этимология, семасиология и т. д.). Вторая рассматривает эволюцию письменно-литературного языка, начиная с первых попыток применения письменности, через этапы развития старописьменного (книжного) языка разных эпох, вплоть до сложения современного литературного языка в его общенародно-разговорной и письменно-литературной формах существования. Для исследования проблем исторической грамматики основными источниками являются письменно-литературные памятники разных эпох и периодов, разных жанров и стилей, а также источники народно-разговорного статуса и характера.

В современной монголистике лингвистическое источниковедение представляется одним из самых перспективных направлений. В связи с этим Г. Д. Санжеев отмечал: «...последующая работа в области монгольского сравнительного и исторического языкознания должна идти в следующих направлениях: во-первых, следует продолжить исследование диалектов и говоров монгольских языков, во-вторых, необходимо значительно расширить углубленное изучение письменных памятников монгольских языков, не ограничиваясь здесь лишь публикацией источников» [Санжеев 1963: 3-4].

Углубленное изучение калмыцкого языка в диахроническом аспекте предполагает в недалеком будущем создание фундаментальных работ по исторической грамматике и истории литературного калмыцкого языка. Для этого хорошей предпосылкой являются исследования ученых [Яхонтова 2010; Сусеева 2003; Гедеева 2004; Кокшаева 2011].

В 2002 г. известные монголисты Джон Крюгер и Роберт Сервис опубликовали книгу «Калмыцкие старинные рукописные документы Исаака Якоба Шмидта», где представлены факсимиле, транскрипция, перевод этих документов на английский язык. Эти письменные памятники, которые в основном охватывают период 1800-1810 гг, хранятся в архиве Общины моравских братьев 
г. Хернхут (Unitas Fratrum — «Объединенные братья») в папке (R.15.R.IIa № 5) [Krueger, Service 2002: IX].

Как отмечает во введении Джон Крюгер, впервые об этом сборнике архивных документов, который состоит из 82 документов (отчасти в зависимости от того, как они подсчитаны), упоминает Э. Хениш в статье «Kalmuckische Fragmente», опубликованной в «Ural-Altaische Jahrbücher» (UAJb - 'Ежегоднике Урало-Алтайского общества') в № 25 (3-4) за 1953 г. (с. 283-294). Им же был дан краткий список и описание (с частичным переводом двух документов) [Krueger, Service 2002: IX]. Опубликованные письма являются ценным источником в том числе и по истории языка.

Цель статьи - рассмотреть некоторые фонетические и морфологические особенности калмыцкого языка по данным опубликованных писем И. Я. Шмидта.

\section{И. Я. Шмидт и калмыки}

Как известно, Якоб Шмидт родился в 1779 г. в Амстердаме, там он получил начальное образование. «В сентябре 1798 г. прибыл в Сарепту в составе шести представителей церковной общины евангелического братства, работал в торговой конторе. По делам службы в Калмыцкой степи провел около трех лет» [Алексеева 2010: 19]. Обладая способностями к языкам, он не только быстро выучил русский и разговорный калмыцкий языки, но и овладел ойратским письмом тодо бичиг (ойр. todo bičiq), ознакомился с устным народным творчеством, обычаями калмыков, поддерживал тесные контакты со знатоками монгольского и тибетского языков. В 1811 г. И. Я. Шмидт переехал в Москву. А в период, когда началась Отечественная война 1812 г., он поселился в Санкт-Петербурге, где работал бухгалтером библейского общества. В то же время И. Я. Шмидт продолжал свои занятия по изучению восточных языков. «Библейское общество поручало ему переводы Евангелий на калмыцкий язык (Евангелия от Иоанна и Матфея, деяния апостолов), составление небольших текстов религиозного содержания. Переведенные и отпечатанные книги отправлялись обществом в Калмыцкую степь. Его как знатока восточных языков пригласили на работу в Академию наук, где он занялся переводом тибетских текстов и составлением словаря тибетского языка. В 1822 г. в письме одному из редакторов «Азиатского журнала» в Париже И. Я. Шмидт сообщает о своем переводе «Истории монголов» Санан-Сэцэна и о своем намерении составить грамматику монгольского и ёлётского («олетского», т. е. ойратского. - E. Б.) языков» [Алексеева 2010: 19]. И. Я. Шмидт занимался научной деятельностью и оставил после себя ряд трудов: «В 1831 г. вышла в свет его „Грамматика монгольского языкае на немецком языке, а в следующем году - на русском. В 1835 г. был издан „Монголо-немецко-русский словарь “. Им переведены на немецкий язык многие монгольские литературные памятники: „История восточных монголовее, „Подвиги Гэсэр-хана ${ }^{e е}$, „Улигерин дала ${ }^{e е}$, а на русский исторические летописи Санан-Сэцэна. В 1826 г. адъюнкт И. Я. Шмидт избран членом-корреспондентом Академии наук, затем удостоился звания академика. Умер ученый в 1847 г. в Петербурге» [Алексеева 2010: 20].

Джон Крюгер считает, что, возможно, все записки и письма, которые были адресованы И. Я. Шмидту, являлись собственностью миссии Сарепты. Если 


\section{Монголоведение • Mongolian Studies • 2020 ๑ T. 12 • № 4}

бы он взял их с собой при отбытии в Москву, они, несомненно, погибли бы в больших московских пожарах 1812 г., когда наступил Наполеон. Следовательно, эти документы были возвращены в Германию после распада Миссии, возможно, после 1830-1840-х гг.

Письма представляют интерес с точки зрения того, что большинство из них имеет датировку. Они охватывают очень короткий период времени, около десяти лет. Большая часть писем - 54 из 80 - отражает переписку с малодербетовскими князьями Тундутовыми, в том числе 18 - от Эрдени Тайши, 27 от Цебека, еще 9 - от Джамба Тайши. Как отмечает Р. Сервис, «судя по семи письмам Джиджи, кажется вероятным, что он является главным должностным лицом Эрдени Тайши, поскольку они озабочены получением почты Эрдени и отправкой официальных сообщений русским; далее касается споров со Шмидтом относительно того, несет ли Эрдени или Джамба ответственность за различные расходы (например, снятие их со счета Эрдени и перевод их на счет Джамбы), обеспечение поставок, необходимых для работы канцелярии, и так далее. Кайиджи также мог быть частью этого административного аппарата, так как его называют носителем писем, и он служит посланником для Чиданг Арши (5 писем), чье собственное положение неясно» (перевод автора. - E. Б.) [Krueger, Service 2002: XIII].

Как известно, 14 октября 1800 г. грамотой императора Павла I Чучей Тундутов был утвержден наместником калмыцкого народа и получил символы власти: саблю, панцирь, соболью шубу и шапку. Также был восстановлен суд Зарго. 13 июля 1802 г. церемония объявления Чучея наместником произошла на р. Зельме в присутствии главного пристава Н. Н. Страхова. 23 мая 1803 г. Чучей умер и наместничество упразднили. В 1805 г. был произведен раздел Дербетовского улуса. К владельцу Малодербетовского Эрдени Тайше отошло 3302 кибитки [История Калмыкии 2009: 482-484].

\section{Некоторые фонетические особенности языка писем из коллекции И. Я. Шмидта}

Несомненно, большой интерес письма представляют с языковой точки зрения как отражение живого произношения. «Язык деловых документов XVIII в., как и других веков, видимо, больше отражает живую речь, чем язык книжной религиозной литературы» [Сусеева 2003: 72]. Кроме того, исследование языка писем неразрывно связано с личностью автора, временем, местом и условиями, в которых он жил.

Материалы текстов писем показывают, что в начале XIX столетия имеет место процесс перехода сочетаний -ои в долгий гласный [u:]. Регулярно употреблявшееся в памятниках XVII - начала XVIII вв. сочетание -ои в исследуемом памятнике встречается крайне редко, например, zügerodo: de:re:n torzoud tala bayixa nüyile:n kerege:rene sarayin xorin-du odunai bi ${ }^{1}$ 'в настоящее время 24 числа этого месяца поеду по делам к торгоутам’ [Krueger, Service 2002: 17]. В большинстве случаев встречается употребление -ии.

То же самое можно сказать и о сочетании -ӧи, которое переходит в долгий гласный [ӥ:]. Между тем, спорадически данное сочетание все же встречается в местоимениях ӧ̈̈ni / töüni: ӧӥni ӧтӧnӧ Ayidarxana:sa xariji yobo:d 'возвра-

\footnotetext{
1 Знак «:» обозначает долготу, знак «-» обозначает отдельное написание падежного аффикса от именной основы.
} 
щаясь из Астрахани' [Krueger, Service 2002: 17]. Текст единственного письма, автором которого является И. Я. Шмидт, интересен тем, что в нем изобилует употребление форм -ои и -ӧй [Krueger, Service 2002: 127]. Мы считаем, что в конце XVIII в. в живом произношении калмыцкого языка шел процесс пе-

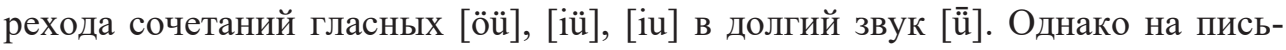
ме они еще имели последовательное употребление. В середине XIX столетия А. А. Бобровников по этому поводу писал: «...так как нет никакой нужды для изображения звуков [u:] и [ӥ:] употреблять двоякие знаки, то мы считаем начертания -ои- и -ӧй- незаконными, и, если можно их допустить, то только в письме, для целей каллиграфических...» [Бобровников 1849: 19].

Д. Крюгер и Р. Сервис отмечают, что имеется и следующая особенность: в словах, где исторически традиционно используется дифтонг -iu, например в слове alčiur, это сочетание в письмах передается иначе - как alčuur [Krueger, Service 2002: 25], что отвечает требованиям живого произношения. Этот факт является ярким свидетельством фонетических изменений, происходивших в живом калмыцком языке на рубеже XVIII-XIX вв. Как отмечает профессор Д. А. Павлов, «...существовавшая система передачи указанных фонем буквами -c-, -z- при сочетании с -i- исчерпала себя...» [Павлов 2000: 115]. Исторически, чтобы передать шипящую аффрикату [с̌] после графемы «чим», необходимо обязательно употребление гласного [i], например, с̌imadu 'тебе'. В тексте же встречаются случаи, в которых используется употребление свистящего согласного [c] без сочетания с гласным [i]. Например: вместо [čimadu], написано [camadu], что близко к современной форме [чамд] [Krueger, Service 2002: 105].

Графический анализ текста памятника позволяет выявить процессы редукции гласных непервых слогов, которые представляют собой «ошибки» авторов. Например, в словах ilge:qse:n / ilege:qsüb во втором случае пропущена гласная [е], причем эта ошибка на странице одного и того же письма [Krueger, Service 2002: 49]. Зафиксировано также в тексте писем «неправильное» употребление исторической формы слове [yeke] ближе к разговорной [ike] [Krueger, Service 2002: 27]. Разнобой в написании кратких гласных в непервых слогах слова во многом объясняется акустической неопределенностью этих гласных. Академик Б. Я. Владимирцов в своей «Сравнительной грамматике» пишет, что «ошибки подобного рода приходится объяснять исключительно тем, что в монгольском языке прошлых времен наблюдалось то же самое явление, что наблюдается и в настоящее время, а именно: гласные не первого слога, не долгие исторически, произносились кратко, они были редуцированные, а следовательно предоставляли большие затруднения для правильного их изображения на письме» [Владимирцов 1989: 107-108].

Некоторые морфологические особенности языка писем из коллекции И. Я. Шмидта

Повелительная форма 2-го лица множественного числа образуется путем присоединения к глагольной основе аффикса -qtün / -qtun. Вопрос о морфологической структуре данного показателя до сих пор не является решенным. Так, Г. Д. Санжеев высказал сомнение по поводу того, что этот показатель путем метатезы возник из древнемонгольского -dqun / -dkün [Санжеев 1953: 102]. В свою очередь В. Л. Котвич, принимая показатель -dqun за старую форму, 


\section{Монголоведение • Mongolian Studies • 2020 ๑ T. 12 • № 4}

предложил, что формант -qtün / -qtun образовался в монгольском языке путем соединения элемента $\boldsymbol{- k}$ - с пришедшим из тюркского языка аффиксом повелительного наклонения 3-го лица обоих чисел -tï, -tu [Котвич 1962: 261-262].

В языке писем И. Я. Шмидта при передаче данной формы зафиксировано несколько случаев использования разговорного форманта -tan, который впо-

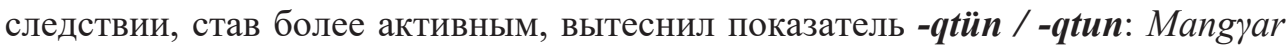
erke biši irji üzüten 'Непременно завтра, приехав, посмотрите' [Krueger, Service 2002: 25].

Причастие прошедшего времени, которое исторически образуется при помощи аффиксов -qsan / -qsen, в тексте писем также стремится к разговорной форме, поэтому нередки случаи употребления форм -san /-sen, которые ближе к современному калмыцкому языку. Например, xara toryon irsen bolxuna 'если прибудет черный шелк’ [Krueger, Service 2002: 15].

Условное деепричастие образуется посредством форманта: -xuna / -küne, причем без исторически долгого второго гласного: ene pošstudu erdeni tayišs $a: s u$ bičiq irküni 'если придет письмо на эту почту от Эрдени-тайши'. Интересно, что в письменных памятниках конца XIX в., например в «Хождении Бааза-багши» [Сказание 1897], условное деепричастие образуется от производных и непроизводных основ посредством форманта -xula: /-küle:

\section{Заключение}

Язык писем И. Я. Шмидта отражает этап развития калмыцкого языка конца XVIII - начала XIX в., характеризующийся закономерным сближением фонетических и грамматических норм письменного литературного языка с живой народной речью. В основе этих процессов лежит редукция кратких гласных непервых слогов слова, которая обусловила в свою очередь количественное сокращение языка, изменение морфологических формантов и т. д. Эти процессы нашли свое отражение в большей или меньшей степени в тексте исследуемого памятника, созданного в духе своего времени.

\section{Литература}

Алексеева 2010 - Алексеева П. Э. О людях и времени. Элиста: КИГИ РАН, 2010. 176 с. Бобровников 1849 - Бобровников $A$. А. Грамматика монгольско-калмыцкого языка. Казань: Унив. тип., 1849. 400 с.

Владимирцов 1989 - Владимирцов Б. Я. Сравнительная грамматика монгольского письменного языка и халхаского наречия. Ведение и фонетика. Л.: Наука, 1989. $433 \mathrm{c}$.

Гедеева 2004 - Гедеева Д. Б. Письма наместника калмыцкого ханства Убаши (XVIII в.). Элиста: Калмыцкий институт гуманитарных исследований РАН, 2004. 194 с.

История Калмыкии 2009 - История Калмыкии с древнейших времен до наших дней: в 3-х томах. Т. 1. Элиста: Изд. дом «Герел», 2009. 848 с.

Кокшаева 2011 - Кокшаева Н. О. Языковые особенности эпистолярного наследия калмыцкого хана Дондук-Даши (середина XVIII в.). Элиста: Изд. дом «Герел», $2011.189 \mathrm{c}$.

Котвич 1962 - Котвич В. Л. Исследование по алтайским языкам. М.: Изд-во иностранной литературы, 1962. $371 \mathrm{c}$.

Павлов 2000 - Павлов Д. А. Вопросы истории и строя калмыцкого литературного языка. Изд. 2-е. Элиста: КалмГУ, 2000. 285 с. 
Санжеев 1953 - Санжеев Г. Д. Сравнительная грамматика монгольских языков. Т. I. М.: Изд-во АН СССР, 1953. 240 с.

Санжеев 1963 - Санжеев Г. Д. Сравнительная грамматика монгольских языков. Глагол. М.: Вост. лит., 1963.266 с.

Сказание 1897 - Сказание о хождении в Тибетскую страну Малодербетского Бааза-бакши. Калмыцкий текст с переводом и примечаниями, составленными А. М. Позднеевым. СПб.: Фак. Вост. яз. Петерб. ун-та, 1897. 260 с.

Сусеева 2003 - Сусеева Д. А. Письма хана Аюки и его современников (1714-1724 гг.): опыт социолингвистического исследования. Элиста: АПП «Джангар», 2003. 456 с.

Яхонтова 2010 - Яхонтова Н. С. Ойратский словарь поэтических выражений. Факсимиле рукописи, транслитерация, введение, перевод с ойратского, словарь с комментариями, приложения Н. С. Яхонтовой. М.: Вост. лит., 2010. 615 с.

Krueger, Service 2002 - Krueger J. R., Service R. G. Kalmyk old-script Documents of Isaak Jacob Schmidt 1800-1810. Todo biciq texts, transcription, translation from the Moravian Archives at Herrnhut. Wiesbaden: Harrassowitz Verlag, 2002. 215 p.

\section{References}

Alekseeva P. E. About People and Time. Elista: Kalmyk Humanities Research Institute (RAS), 2010. 176 p. (In Russ.)

Bobrovnikov A. Grammar of Kalmyk Mongolian. Kazan: Imperial Kazan University, 1849. 400 p. (In Russ.)

Gedeeva D. B. Letters of the Kalmyk Viceroy Ubashi: $18^{\text {th }}$ Century. Elista: Kalmyk Humanities Research Institute (RAS), 2004. 194 p. (In Russ.)

Kokshaeva N. O. Epistolary Heritage of the Kalmyk Khan Donduk-Dashi, Mid-18 ${ }^{\text {th }}$ Century: A Case Study of Language Features. Elista: Gerel, 2011. 189 p. (In Russ.)

Kotwicz W. L. A Study of Altaic Languages. Moscow: Publishing House of Oriental Literature, 1962. 371 p. (In Russ.)

Krueger J. R., Service R. G. Kalmyk Old-Script Documents of Isaak Jacob Schmidt 1800 1810: Todo Biciq Texts, Transcription, Translation from the Moravian Archives at Herrnhut. Wiesbaden: Harrassowitz Verlag, 2002. 215 p. (In Eng.)

Maksimov K. N., Ochirova N. G. (eds.) History of Kalmykia: From Earliest Times to the Present Days. In 3 vols. Vol. 1. Elista: Gerel, 2009. 848 p. (In Russ.)

Pavlov D. A. Kalmyk Literary Language: Issues of History and Structure. $2^{\text {nd }}$ ed. Elista: Kalmyk State University, 2000. 285 p. (In Russ.)

Sanzheev G. D. Comparative Grammar of the Mongolic Languages. Vol. I. Moscow: USSR Academy of Sciences, 1953. 240 p. (In Russ.)

Sanzheev G. D. Comparative Grammar of the Mongolic Languages: Verb. Moscow: Vostochnaya Literatura, 1963. 266 p. (In Russ.)

Suseeva D. A. Letters of Khan Ayuka and His Contemporaries, 1714-1724: A Sociolinguistic Study. Elista: Dzhangar, 2003. 456 p. (In Russ.)

The Tale of How Ven. Baaza Bakshi of the Baga Dorbet Undertook a Pilgrimage to the Land of Tibet. A. Pozdneev (transl., comment.). St. Petersburg: Imperial St. Petersburg University, 1897. 260 p. (In Kalm. and Russ.)

Vladimirtsov B. Ya. Classical Mongolian and Khalkha Dialect: A Comparative Grammar. Introduction and Phonetics. Leningrad: Nauka, 1989. 433 p. (In Russ.)

Yakhontova N. S. The Oirat Dictionary of Poetic Expressions. Moscow: Vostochnaya Literatura, 2010. 615 p. (In Oir. and Russ.) 